\title{
Participación en el Foro-Exhibición Internacional de los Sistemas Culturales Territoriales
}
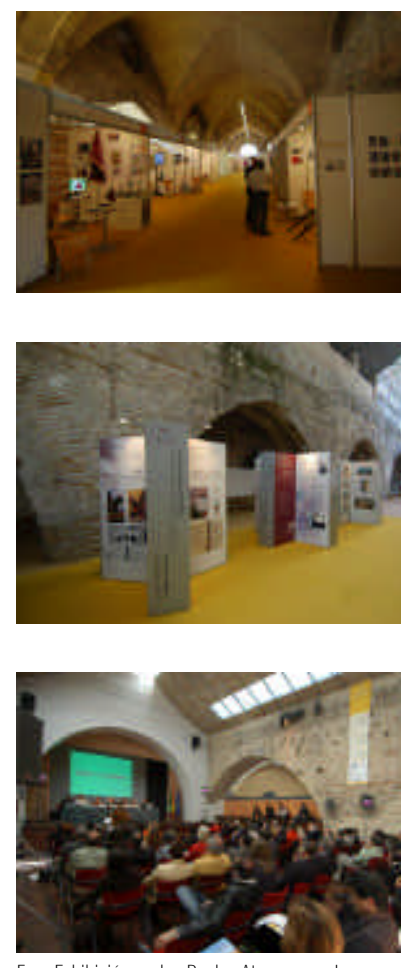

Foro-Exhibición en las Reales Atarazanas. Imagen: Eugenio Fernández Ruiz. Fuente: IAPH.
Las Reales Atarazanas de Sevilla fueron testigo durante los pasados 24, 25 y 26 de octubre de un Foro-Exhibición Internacional dedicado a la gestión, puesta en valor y promoción del patrimonio cultural a través del desarrollo de Sistemas Culturales Territoriales. Dicho evento formaba parte de las actividades incluidas en el proyecto DELTA, patrocinado por el programa europeo MEDA - Euromed Heritage y en el que participa la Consejería de Cultura de la Junta de Andalucía a través del Instituto Andaluz del Patrimonio Histórico.

El Foro-Exhibición DELTA ha sido una excelente ocasión para reunir y presentar diversas experiencias e iniciativas realizadas en el área mediterránea relacionadas con procesos de desarrollo de sistemas culturales que comparten un mismo enfoque territorial integrado. El objetivo era facilitar que distintas organizaciones presentaran los contenidos y los resultados más interesantes de sus actividades, para promover un intercambio amplio de experiencias y acercar la visión de los sistemas culturales territoriales a los responsables institucionales y al resto de operadores culturales y económicos.

La Exhibición DELTA puso el broche final a un ambicioso proyecto que ha facilitado la experimentación práctica de proyectos territoriales integrados a través de la transferencia de conocimientos y metodologías de trabajo entre ambas orillas del Mediterráneo.

El evento ha contado con una amplia representación de organizaciones públicas y privadas que están trabajando activamente en todo el área Mediterránea, con una destacada presencia de proyectos actualmente en marcha en el territorio andaluz. En Sevilla se dieron cita más de 50 expositores provenientes de 9 países de la cuenca medi- terránea; Argelia, Marruecos, Malta, Palestina, Israel, Francia, Grecia, Italia y España.

La Consejería de Cultura de la Junta de Andalucía, que destinó un espacio relevante para la presentación de algunos de sus proyectos más importantes, como la Red de Yacimientos Arqueológicos o la Red de Museos, estuvo acompañada por una nutrida representación de iniciativas netamente andaluzas. Son de destacar los stands presentados por la Ruta de la Bética Romana, el proyecto Peregrinus, Viaje al País de los íberos o la Ruta de los Castillos y Batallas, entre otros.

La Exhibición se vio completada con la celebración del Foro DELTA (Desarrollo de Sistemas Culturales Territoriales), durante el cual se dieron a conocer los resultados globales del proyecto y se propusieron interesantes orientaciones para la implementación de un enfoque territorial integrado en el marco de las políticas locales de desarrollo.

Los invitados internacionales al Foro pudieron conocer de primera mano algunos proyectos de puesta en valor del patrimonio local a través de visitas guiadas al Conjunto Arqueológico de Itálica, al Monasterio de San Isidoro del Campo y a la ciudad histórica de Carmona.

Como colofón durante la última jornada del Foro y exhibición DELTA fue presentado el proyecto de creación de una nueva Red de Sistemas Culturales Territoriales.

Héctor Sáenz de Lacuesta

Área de Cooperación del IAPH

\section{El Patronato de Arte - Asociación Amigos de los Museos de Osuna premia la labor del IAPH}

La Asociación Amigos de los Museos de Osuna, Extensión Cultural del Patronato de Arte, ha concedido el sexto premio "Manuel Rodríguez-Buzón", máxima distinción de la entidad, al Instituto Andaluz del Patrimonio Histórico en atención "a los relevantes méritos acreditados en la defensa y restauración del patrimonio histórico de Andalucía y en particular de esta ciudad de Osuna". Los galardones de ediciones anteriores han recaído en las personas de J uan Ramón Aragón -concedido a título póstumo-, J avier Herrera Govantes -impulsor de la vuelta a Osuna de la Universidad-, Manuel
Olmedo -vicepresidente actual de la Asociación Amigos del Museo de Osuna-, Rafael Manzano Catedrático de la ETS Arquitectura de Sevilla- y Fidel J. López Aparicio-Fundador de la Academia de Ciencias Matemáticas, Físico-Químicas y Naturales de Granada-

El acto de entrega del galardón, que consiste en un pergamino enmarcado realizado por Fernando Marmolejo, tuvo lugar el pasado 18 de diciembre de 2005, coincidiendo con el XIV Encuentro de Navidad de los Amigos de los Museos de Osuna. 